\title{
Sphere-Forming Capacity as an Enrichment Strategy for Epithelial-Like Stem Cells from Equine Skin
}

\author{
Bizunesh M. Borena ${ }^{a, b}$ Evelyne Meyer ${ }^{c}$ Koen Chiers $^{d}$ Ann Martens ${ }^{e}$ \\ Kristel Demeyere ${ }^{c}$ Sarah Y. Broeckx ${ }^{f, g}$ Luc Duchateau $^{\mathrm{a}}$ Jan H. Spaas ${ }^{\mathrm{f} g}$ \\ aDepartment of Comparative Physiology and Biometrics, Faculty of Veterinary Medicine, Ghent \\ University, Merelbeke, Belgium, ${ }^{b}$ Department of Veterinary Laboratory, College of Agriculture and \\ Veterinary Science, Ambo University, Ethiopia, 'Department of Pharmacology, Toxicology and \\ Biochemistry, Faculty of Veterinary Medicine, Ghent University, Merelbeke, Belgium, dDepartment \\ of Pathology, Bacteriology and Poultry Diseases, Faculty of Veterinary Medicine, Ghent University, \\ Merelbeke, Belgium, eDepartment of Surgery and Anesthesiology of Domestic Animals, Faculty of \\ Veterinary Medicine, Ghent University, Merelbeke, Belgium, ${ }^{\mathrm{f}}$ Global Stem cell Technology, Meldert- \\ Lummen, Belgium, 9Pell Cell Medicals, Opglabbeek, Belgium
}

\section{Key Words}

Purification • Skin • Epithelial $•$ Stem Cells $•$ Horse $•$ Sphere formation

\begin{abstract}
Background: Mammal skin plays a pivotal role in several life preserving processes and extensive damage may therefore be life threatening. Physiological skin regeneration is achieved through ongoing somatic stem cell differentiation within the epidermis and the hair follicle. However, in severe pathological cases, such as burn wounds, chronic wounds, and ulcers, the endogenous repair mechanisms might be insufficient. For this reason, exogenous purification and multiplication of epithelial-like stem/progenitor cells (EpSCs) might be useful in the treatment of these skin diseases. However, only few reports are available on the isolation, purification and characterization of EpSCs using suspension cultures. Methods: In the present study, skin was harvested from 6 mares and EpSCs were isolated and purified. In addition to their characterization based on phenotypic and functional properties, sphere formation was assessed upon isolation, i.e. at passage $0\left(P_{0}\right)$, and at early $\left(P_{4}\right)$ and late $\left(P_{10}\right)$ passages using different culture conditions. Results: On average $0.53 \pm 0.28 \%$ of these primary skin-derived cells showed the capacity to form spheres and hence possessed stem cell properties. Moreover, significantly more spheres were observed in EpSC medium versus differentiation medium, corroborating the EpSCs' privileged ability to survive in suspension. Furthermore, the number of cells per sphere significantly increased over time as well as with subsequent passaging. Upon immunophenotyping, the presumed EpSCs were found to co-express cytokeratin (CK) 14, Casein kinase 2 beta and Major Histocompatibility Complex (MHC) I and expressed no pan CK and wide CK. Only a few cells expressed MHC II. Their differentiation towards keratinocytes (at $\mathrm{P}_{4}$ and $\mathrm{P}_{10}$ ) was confirmed based on co-expression of CK 14, Casein kinase 2 beta, pan CK and wide CK. In one of six isolates, a non-EpSC cell type was noticed in adherent culture. Although morphological features and immunohistochemistry (IHC) confirmed a keratinocyte
\end{abstract}


phenotype, this culture could be purified by seeding the cells in suspension at ultralow clonal densities (1 and 10 cells $/ \mathrm{cm}^{2}$ ), yet with a significantly lower sphere forming efficiency in comparison to pure EpSCs $(P=0.0012)$. Conclusion: The present study demonstrated sphere formation as a valuable tool to purify EpSCs upon their isolation and assessed its effectiveness at different clonal seeding densities for eliminating a cellular contamination.

Copyright (C) 2014 S. Karger AG, Basel

\section{Introduction}

Adult stem cells possess a low antigenicity [1] and can be isolated from a variety of sources including bone marrow [2, 3], adipose tissue [4], peripheral blood [5] and skin [6]. Unlike embryonic stem cells, little or no ethical issues are related to the use of their adult counterparts. Being the body's largest organ, the skin is a highly accessible source and the largest reservoir of epithelial stem cells (EpSCs), at least in humans [7]. Furthermore, their surprisingly diverse differentiation potential has also contributed to a significant recent interest in adult skin stem cells [8]. Permanently residing EpSCs in mammalian skin are able to differentiate into multiple lineages and have been reported in the epidermis [9], hair follicle [10] as well as dermis [6].

Like stem cells from other tissues, epidermal EpSCs play a central role in tissue homeostasis and wound repair, but also represent a major target of tumor initiation and gene therapy [11]. These EpSCs can differentiate into interfollicular epidermis, hair follicles and sebaceous glands [12]. The extensive regenerative capacities of the epidermis is due to the presence of EpSCs that continuously produce keratinocytes, which further undergo terminal differentiation towards a keratinized layer and provide the skin's barrier properties in mammals [13]. Furthermore, the epidermis contains a population of stem cells with apparently different levels of maturity [14]. This heterogeneous population displays subpopulations of a different morphology than its more differentiated progeny at the homing site [15]. Interestingly, the bulge of the hair follicle is a major repository of skin keratinocyte stem cells and the latter have been regarded as the ultimate EpSCs [10, 11, $16,17]$. However, it should be emphasized that lineage tracing in vivo demonstrated the existence of interfollicular stem cells $[18,19]$ and indicated that epidermal and hair follicle stem cells represent distinct populations [18].

Stem cells are being isolated from different tissues, have been evaluated in numerous human clinical trials and are since recently commercially used in veterinary medicine to treat horses and dogs [1]. However, purification of stem cells is technically difficult because of their scarcity in the tissue of origin and the lack of universal morphologic traits for stem cells [20]. Many of the methods developed for the isolation and analysis of specific cell types cannot be used for medical experimentation on living materials because of the damaging nature of these techniques, such as isotope radiation and cell fixation [21]. For isolation of EpSCs, in vitro methods describe the use of (i) colony forming culture to localize multipotent stem cells in the hair follicle bulge region [22], (ii) Hoechst exclusion technique to isolate a side population in the hair follicles [23], (iii) cell sorting using CD71 and $\alpha 6$-integrin expression markers for harvesting keratinocyte stem cells [24] and (v) sphere formation [9].

Once skin-derived precursor cells differentiate, they lose typical stem cell properties and their survival in suspension is substantially reduced [25]. In the mammary gland, another epidermal organ, so-called mammospheres are also intensively studied for stem/ progenitor cell purification purposes [26, 27]. Unfortunately, a major disadvantage of this 3 -D technique is contamination with other adult cell types surviving between the sphereforming stem cells [26]. Moreover, no reports are available concerning sphere forming capacities of skin-derived EpSCs and their differentiated progeny during long-term serial passaging. Furthermore, only limited information is available concerning cell impurities in skin-derived sphere cultures. For all these reasons, this study was designed to extend the existing knowledge of EpSC purification through sphere formation in different culture circumstances. 


\section{Materials and Methods}

\section{Donor animals and skin harvesting}

Six healthy French trotter mares with an age between 5 and 7 years and in good general health condition (no clinical or hematological signs of infections) were used for skin sample collection. The isolation and characterization of skin-derived EpSCs was performed as previously described [26, 9] with some minor modifications. Briefly, horses were sedated with an intravenous injection of detomidine hydrochloride $\left(0.01 \mathrm{mg} / \mathrm{kg}\right.$, Medesedan ${ }^{\circledR}, \mathrm{VIRBAC}$, Belgium $)$ and the analgesic butorphanol $(0.01 \mathrm{mg} / \mathrm{kg}$, Dolorex $\AA$, Intervet, Belgium). After surgical preparation (clipping, scrubbing and disinfecting) and local anesthesia of the neck region with 4\% Procaine-Adrenalin, one full thickness skin sample of about $2 \mathrm{~cm}^{2}$ was excised. Samples were kept in transport medium consisting of Hank's balanced salt solution (HBSS, Gibco) with $2 \%$ of penicillin-streptomycin-amfotericine B (P/S/A, Sigma-Aldrich). The experimental procedure was approved by the ethical committee of Global Stem Cell Technology (EC_2012_002, EC_2013_003 and EC_2014_001) and the Faculty of Veterinary Medicine, Ghent University (EC_2014_020).

\section{Isolation and culture of skin-derived epithelial-like stem cells}

In the laboratory, the samples were maintained at $4^{\circ} \mathrm{C}$ overnight in $0.25 \%$ trypsinethylenediaminetetraacetic acid (EDTA) (Gibco) solution with the hair side down. Afterwards, the epidermis was mechanically disconnected from the dermis by deep scraping using sterile scalpel and forceps on a sterile petri dish. Subsequently, a second enzymatic dissociation step with $1 \%$ collagenase III (Worthington Biochemical Corporation) at $37^{\circ} \mathrm{C}$ for 60 minutes was performed in order to remove epidermal cells. The suspension was poured through a $40 \mu \mathrm{m}$ filter (BD Falcon) in a $50 \mathrm{ml}$ tube containing $2 \mathrm{ml}$ of FBS to inactivate the collagenase III and washed by centrifugation at $300 \mathrm{G}$ for 8 minutes at room temperature. The pellets were re-suspended in epithelial-like stem cell (EpSC) medium, consisting of Dulbecco's modified Eagle's medium (DMEM)/F12 (Gibco), 20\% fetal bovine serum (FBS, Gibco), 2\% P/S/A, 20 ng/ml human recombinant-basic fibroblast growth factor (hr-bFGF) and $20 \mathrm{ng} / \mathrm{ml}$ epidermal growth factor (EGF) (all from Sigma-Aldrich). The suspension was then filtered again and cells were counted using Trypan blue staining (1:1 dilution). Subsequently, the cells were cultured on ultralow attachment plates to induce sphere formation. After 7 days of suspension culture, spheres were centrifuged and seeded on adhesive tissue culture flasks for further characterization.

\section{Sphere formation assay}

From the cells harvested by the procedure above, an average of $(0.4 \pm 0.2) \times 10^{5}$ cells $/ \mathrm{cm}^{2}$ were planted per well of an ultralow attachment 6-well plate for all 6 skin samples (Corning, Elscolab) in EpSC medium to induce primary spheres. The spheres were counted at day 4 and 7 and the medium was refreshed by means of centrifugation at $300 \mathrm{G}$ for $8 \mathrm{~min}$ at both time points. Sphere forming efficiency was calculated by dividing the average number of spheres counted in a well by the number of cells planted and multiplied by 100 to express as a percentage. After the first sphere cycle ( 7 day culture on ultralow attachment plates), all spheres were collected and planted onto adherent tissue culture flasks in EpSC medium. Upon 80\% confluency, the adherent cells were trypsinized with $0.25 \%$ trypsin-EDTA and cultured in fresh medium from passage 1 $\left(\mathrm{P}_{1}\right)$ to $\mathrm{P}_{10}$. At $\mathrm{P}_{4}$ and $\mathrm{P}_{10}$ cells were seeded in duplicate at a clonal density of $100 \mathrm{cells} / \mathrm{cm}^{2}$ on 6 -well ultralow attachment plates to initiate a second and third sphere cycle for all 6 skin samples, respectively. The second and third sphere cycle were performed in both EpSC and differentiation medium. Differentiation medium consisted of DMEM/F12 (Gibco), 20\% FBS (Gibco), $5 \mu \mathrm{g} / \mathrm{ml}$ insulin, $1 \mu \mathrm{g} / \mathrm{ml}$ hydrocortisone and $0.1 \mathrm{mM}$ betamercaptoethanol (all from Sigma-Aldrich). The medium was refreshed every two days and the following parameters were recorded in 10 fields on day 1, 4 and 7 post-seeding: number of cell units/field (a separate cell or a sphere is counted as 1 cell unit at each time point), number of spheres/field and number of cells/ sphere (all at 200x magnification).

\section{Purification of EpSCs}

For purification of an impure EpSC culture, adherent cells from $\mathrm{P}_{10}$ of this culture and a pure culture as a positive control were cultured in suspension on 6-well ultralow attachment plates at different densities: 1 cell $/ \mathrm{cm}^{2}$ (=10 cells/6-well), 10 cells $/ \mathrm{cm}^{2}$ (=100 cells/6-well) and 100 cells $/ \mathrm{cm}^{2}$ (=1000 cells/6-well) using EpSC medium. The experiment was performed three times in triplicate for each seeding density and the 
number of spheres and number of cells/sphere were compared on day 1, 4 and 7 post-seeding with a pure culture. On day 7 , the spheres were centrifuged and reseeded on adherent tissue culture plates and grown for 7 days to assess morphological differences and perform IHC.

\section{Population doubling time (PDT)}

After culturing the spheres in adherent tissue culture flasks, EpSCs were trypsinized at $80 \%$ confluency using $0.25 \%$ trypsin-EDTA. Cells were counted using trypan blue staining and subcultured at $1 \times 10^{4} / \mathrm{cm}^{2}$ until $\mathrm{P}_{10}$. The proliferation rate was quantified using the population doubling time (PDT), which was calculated for each passage from $\mathrm{P}_{1}$ to $\mathrm{P}_{10}$ as previously described by Martinello et al. [28] and Spaas et al. [5], using the formula: $T /\left[\log \left(\mathrm{N}_{\mathrm{f}} / \mathrm{N}_{\mathrm{i}}\right) / \log 2\right]$, where $\mathrm{T}$ is the time in days, $\mathrm{N}_{\mathrm{f}}$ the final number of cells and $\mathrm{N}_{\mathrm{i}}$ the initial number of cells.

\section{Flow cytometry assay}

A flow cytometric technique was used to characterize sphere-derived cells for the expression of major histocompatibility complex (MHC) I and MHC II. Adherent cells from $\mathrm{P}_{4}$ and $\mathrm{P}_{10}$ were first detached using $0.25 \%$ trypsin-EDTA (Gibco) and frozen at 400,000 cells per vial using 10\% DMSO (Sigma) as a cryoprotectant (for analysis of the different time points at the same time). Per series, 400,000 cells were thawed and labeled with the following primary antibodies: mouse anti-horse MHC class I IgG 2a $_{\text {a }}$ Washington State University, 1:50) and mouse anti-horse MHC class II IgG $(A b d$ Serotec, 1:50). Cells were incubated with the primary antibodies for 15 minutes on ice in the dark and washed twice in washing buffer, consisting of DMEM with 1\% bovine serum albumin (BSA). Rabbit anti-mouse-FITC (Dako, 1:40) antibodies were used to identify positive cells after 15 minutes of incubation on ice in the dark. Finally, all cells were washed three times in washing buffer and at least 10,000 cells were evaluated using the FACSCanto ${ }^{\mathrm{TM}}$ flow cytometer (Becton Dickinson). All analyses were based on (i) autofluorescence and (ii) control cells incubated with isotypespecific IgG's, in order to establish the background signal. All isotypes were matched to the immunoglobulin subtype and used at the same protein concentration as the corresponding antibodies. To evaluate cell viability the cell impermeable DNA dye propidium iodide (Sigma-Aldrich, $1 \mu \mathrm{g} / \mathrm{ml}$ ) was added just before measurement.

\section{Induction of differentiation}

Differentiation of the isolated cells towards keratinocytes was induced using a distinct differentiation protocol for EpSCs developed by Broeckx et al. [9]. Briefly, adherent cells from $\mathrm{P}_{4}$ and $\mathrm{P}_{10}$ were trypsinized using $0.25 \%$ trypsin-EDTA and EpSCs were seeded into 24 -well plates at a density of $2.5 \times 10^{3}$ per $\mathrm{cm}^{2}$. The cells were induced in differentiation medium for 7 days and the medium was refreshed every 2 days. In parallel to this, EpSCs were also cultured in similar plates at the same density using EpSC medium as a control.

Immunohistochemistry (IHC)

To identify whether the skin-derived cells expressed previously reported EpSC markers [9] and to qualitatively assess the success of keratinocyte differentiation and EpSC purification, IHC at $\mathrm{P}_{4}, \mathrm{P}_{10}$ and $\mathrm{P}_{11}$ was performed. Adherent cells were washed with HBSS, fixed for 10 minutes with $4 \%$ paraformaldehyde and permeabilized for 2 minutes with $0.1 \%$ Triton X, both at room temperature. Cells were then incubated with hydrogen peroxide for 5 minutes followed by washing with HBSS before incubation for 2 hours at room temperature with the following primary mouse IgG $_{1}$ monoclonal antibodies: anti-human cytokeratin 14 (CK 14) (Abcam, clone LL002, 1:50) and anti-human Pan CK (Dako, clone, AE1/AE3, 1:50) and the following rabbit antibodies: anti-human Wide CK (Abcam, 1:50) and anti-human IgG Ab casein kinase $2 \beta$ (CK-2 $\beta$ ) (Abcam, clone EP1995Y, 1:50). After washing with HBSS, secondary ready to use either goat anti-mouse or anti-rabbit peroxidase (PO)-linked antibodies (Dako) -depending on the primary antibody used- were added and incubated for 30 minutes at room temperature. Finally, 3, 3'-diaminobenzidine (DAB) was added for 2-10 minutes and a counter staining with hematoxylin was performed to visualize the surrounding cells. Identical staining performed on undifferentiated EpSCs was used as a control for the differentiation experiment and background staining was assessed by using the proper isotype-specific IgG's. All isotypes were matched to the immunoglobulin subtype and used at the same protein concentration as the corresponding antibodies. The staining was then observed using an inverted light microscope and pictures were taken using a digital microscope camera. 


\section{Statistical analysis}

The statistical analysis for the sphere formation assay and the population doubling time was based on the mixed model with horse as random effect and medium, time, sphere cycle and the two-way interactions as fixed effects. For testing the difference in sphere forming efficiency between a pure and impure EpSC isolate, a fixed effects model was fitted with the number of seeded cells $(10,100$ and 1000), isolate (pure vs impure) and their interaction as fixed effects factors. SAS Version 9.3 was used for the analyses (SAS/STAT Software, Version 9.3, SAS Institute Inc.). The relationship between the number of cell units/field and the number of spheres/field was determined by the Pearson correlation coefficient. Values are given as mean \pm standard error and a global significance level of $5 \%$ was used.

\section{Results}

\section{Isolation and culture of skin-derived epithelial-like stem cells}

Presumed EpSCs were isolated from all 6 equine skin samples following mechanical and enzymatic digestion. First, the isolated primary skin-derived epithelial cell suspensions were grown in non-adherent (spherical) culture conditions for stem cell purification. Secondly, these spheres were further expanded in adhesive culture circumstances. The impurities detected in one of the six horses were thirdly effectively purified as reported in detail in the "Purification of EpSCs" section.

The first and thus very small "spheres" consisting of on average 2 cells/sphere were observed in all cultures as early as 1 day post seeding. With time the size of these initial spheres significantly increased at all passages as illustrated in Fig. 1. At $\mathrm{P}_{0}$ other cell structures such as floating fragments, keratinocytes and melanocytes were visible and no adherent cells could be noticed in all suspension cultures (Fig. 1). Upon subsequent seeding on adherent tissue culture flasks, the cells in the spheres dispersed and reached $70-80 \%$ confluence at approximately 4-5 days post-seeding. Moreover, trypsinization and reseeding from adherent plates on ultralow attachment plates resulted in the formation of subsequent generations of spheres (Fig. 1).

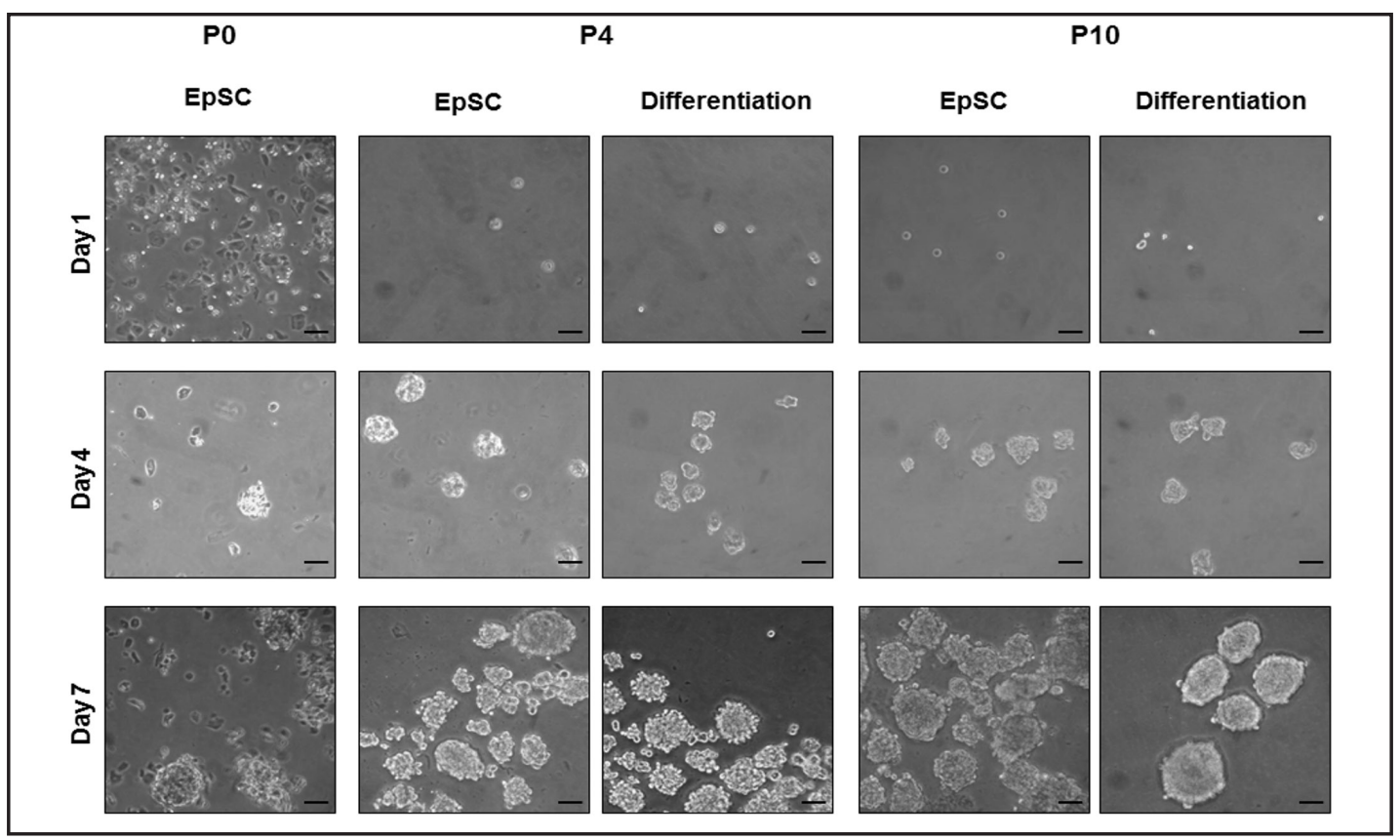

Fig. 1. Sphere formation in epithelial stem cell (EpSC) and differentiation medium at different passages cultured on ultralow attachment plates for 7 days. Primary spheres in EpSC medium at Passage (P) 0, second cycle sphere formation in EpSC and differentiation medium at P4 and third cycle sphere formation in both media at P10. The picture indicates the increase in number of cells/sphere over time (200x magnification, scale bar $=50 \mu \mathrm{m}$ ). 
Sphere formation assay

To test the self-renewal capacity of the presumed EpSCs, the sphere-initiating capacity of serially passaged cells cultured as spheres was assessed (Fig. 1 and 2). A similar assay has been previously used for the characterization of human mammospheres [26]. An average sphere-forming efficiency of $0.53 \pm 0.28 \%$ (means $\pm S D, n=6$; Table 1 ) was recorded from the primary skin-derived epithelial cells seeded on the non-adherent plates at an average density of $0.4 \times 10^{5}$ cells $/ \mathrm{cm}^{2}$. Sphere formation was successful at $\mathrm{P}_{4}$ (second sphere cycle) and $P_{10}$ (third sphere cycle) from seeding 100 cells $/ \mathrm{cm}^{2}$ (Fig. 1), which indicated that these cultured cells were capable of self-renewal, proliferation and clonal expansion in suspension. The number of cell units/field increased over time in EpSC medium, but decreased over time in the differentiation medium $(\mathrm{P}<0.0001)$. By day 7 , a significantly $(\mathrm{P}<0.0001)$ higher number of cell units/field was observed in EpSC medium versus differentiation medium (Fig. 2A). Regardless the medium used, the number of cell units/field was significantly $(\mathrm{P}<0.0001)$ higher at the second cycle $\left(\mathrm{P}_{4}\right)$ than at the third cycle $\left(\mathrm{P}_{10}\right)$ (Fig. 2A). The number of cells/sphere significantly increased from day 4 to day 7 post-seeding $(\mathrm{P}<0.0001)$ and with sphere cycle $(\mathrm{P}<0.0001$ and Fig. $2 \mathrm{~B})$, and the increase was larger in the third cycle $(\mathrm{P}$ $<0.0001$ ).

Regarding the number of spheres/field on both day 4 and day 7 , this parameter was significantly higher in EpSC than in differentiation medium $(\mathrm{P}=0.008, \mathrm{P}<0.0001$, respectively and Fig. $2 \mathrm{C})$. A strong correlation $\left(\mathrm{R}^{2}=0.9\right)$ between the number of cell units/field and of the number of spheres/field existed in both media. However, unlike the number of cell units/ field, the number of spheres/field was not significantly affected by sphere cycle $(P=0.203$, data not shown). Overall, these data indicated that presumed EpSCs clonally expanded in suspension, however, they experienced difficulties in sphere formation when going into the differentiation process.

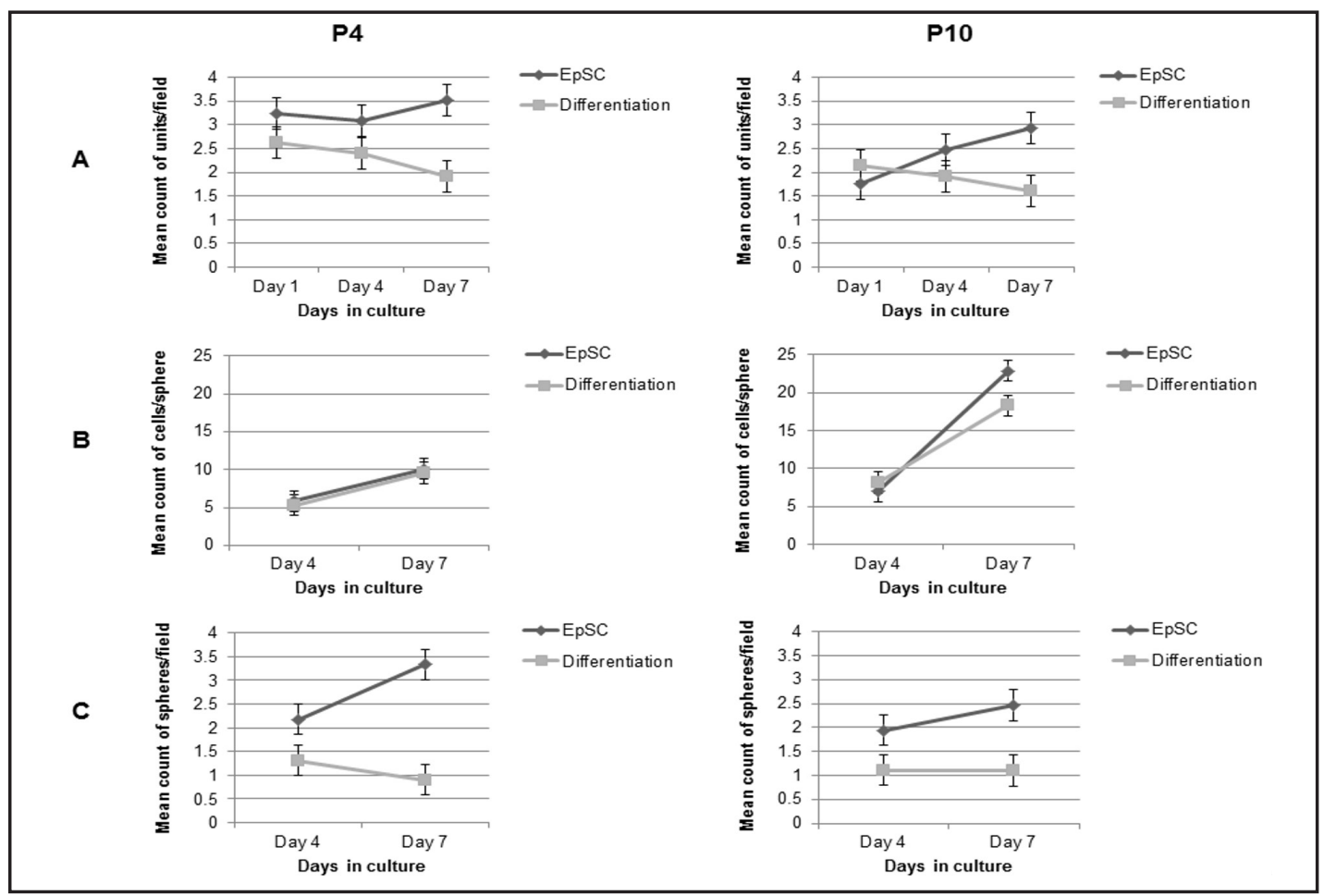

Fig. 2. Epithelial-like stem cell (EpSC) proliferation assays. Sphere generating cells from adherent culture of passage 4 and 10 were cultured in suspension at a density of 100 cells $/ \mathrm{cm}^{2}$ in ultralow attachment plates using EpSC and differentiation medium to generate $2^{\text {nd }}(\mathrm{P} 4)$ and $3^{\text {rd }}(\mathrm{P} 10)$ cycle of spheres. Number of units/ field (A), number of cells/sphere (B) and number of spheres/field (C) were counted per 200x magnification field and compared between both media. 
Table 1. Sphere forming efficiency (SFE) from the primary skin-derived epithelial cells planted on non-adherent plates. The SFE (in \%) was calculated by dividing the average number of spheres counted per well by the seeded cells multiplied by 100

\begin{tabular}{cccc}
\hline Horse number & Seeding density & No. of spheres & SFE $(\%)$ \\
\hline 1 & $0.15 \times 10^{6}$ & 1089.17 & 0.73 \\
2 & $0.75 \times 10^{6}$ & 968.15 & 0.13 \\
3 & $0.54 \times 10^{6}$ & 2299.36 & 0.43 \\
4 & $0.35 \times 10^{6}$ & 1452.23 & 0.42 \\
5 & $0.26 \times 10^{6}$ & 2420.38 & 0.95 \\
6 & $0.45 \times 10^{6}$ & 2299.36 & 0.51 \\
\hline Average & $0.42 \times 10^{6}$ & 1754.78 & 0.53 \\
Standard deviation & $0.21 \times 10^{6}$ & 661.74 & 0.28 \\
\hline
\end{tabular}

Population doubling time of EpSCS

The population doubling time (PDT) of isolated skin-derived epithelial cells from fresh adherent cultures (i.e. not cryopreserved) was used as an indicator of self-renewal and proliferation potential and was calculated from $\mathrm{P}_{1}$ up to $\mathrm{P}_{10}$ (Table 2). Our results indicate that there was no statistically significant $(\mathrm{P}=0.319)$ difference in the population doubling time of the different passages. The PDT in the adherent cultures for all the passages was positive and varied between $0.89 \pm 0.13$ days and $1.39 \pm 0.35$ days (means $\pm S D, n=6$; Table 2 ).

Table 2. Population doubling time (PDT) in days of 6 adherent EpSC cultures calculated from passage (P) 1 to 10. STD: standard deviation

\begin{tabular}{cccccccccccc}
\hline Horse & P1 & P2 & P3 & P4 & P5 & P6 & P7 & P8 & P9 & P10 \\
\hline 1 & 1.28 & 0.68 & 1.11 & 1.19 & 1.12 & 1.24 & 1.11 & 1.01 & 2.02 & 0.70 \\
2 & 0.93 & 0.99 & 1.20 & 1.17 & 1.30 & 1.48 & 1.48 & 1.30 & 1.50 & 0.94 \\
3 & 1.12 & 1.03 & 1.02 & 1.11 & 1.11 & 1.12 & 1.38 & 1.16 & 1.31 & 1.04 \\
4 & 1.14 & 0.78 & 1.09 & 1.08 & 1.14 & 1.13 & 1.23 & 1.03 & 1.14 & 0.90 \\
5 & 1.51 & 0.96 & 1.01 & 0.97 & 1.20 & 1.04 & 1.25 & 1.08 & 1.04 & 0.87 \\
6 & 1.10 & 0.88 & 1.22 & 1.12 & 1.27 & 1.13 & 1.38 & 1.13 & 1.31 & 0.92 \\
\hline Average & 1.18 & 0.89 & 1.11 & 1.11 & 1.19 & 1.19 & 1.31 & 1.12 & 1.39 & 0.89 \\
STD & 0.20 & 0.13 & 0.09 & 0.08 & 0.08 & 0.15 & 0.13 & 0.10 & 0.35 & 0.11 \\
\hline
\end{tabular}

\section{Immunophenotyping of the isolated and differentiated cells}

Flow cytometric analysis was performed to immunophenotypically characterize the isolated skin-derived epithelial cells and to evaluate their expression of typical immunological proteins over time and after differentiation towards keratinocytes. Compared to the relevant isotype controls, most of the presumed EpSCs and differentiated cells expressed MHC I concomitant with only a limited number of cells expressing MHC II at $\mathrm{P}_{4}$ as well as at $\mathrm{P}_{10}$ (Fig. $3)$. No significant differences in number of cells expressing MHC I and II could be noticed between the two cell types at different time points (Fig. 3).

\section{Immunohistochemistry of EpSCs and cells differentiated towards keratinocytes}

The immunophenotypic characterization of sphere-derived cells and their differentiation potential was evaluated using immunohistochemistry analysis. Accordingly, the isolated undifferentiated skin-derived epithelial cells, which were used as control for the differentiation experiments, were negative for typical keratinocyte markers, namely Pan CK and Wide CK [29] while staining positive for the epithelial markers Casein kinase $2 \beta$ [30] and CK 14 (Fig. 4). Differentiated cells on the other hand, were positive for all three cytokeratines tested i.e. CK 14, Pan CK and Wide CK as well as for the epithelial marker Casein kinase $2 \beta$. No positive staining cells were detected in the undifferentiated as well as differentiated cell culture upon relevant isotype control staining. Morphologically, the undifferentiated cells were elongated or typically spindle-shaped, whereas the differentiated cells were more stretched, stellate-shaped and formed cobblestone-like cells (Fig. 4). 


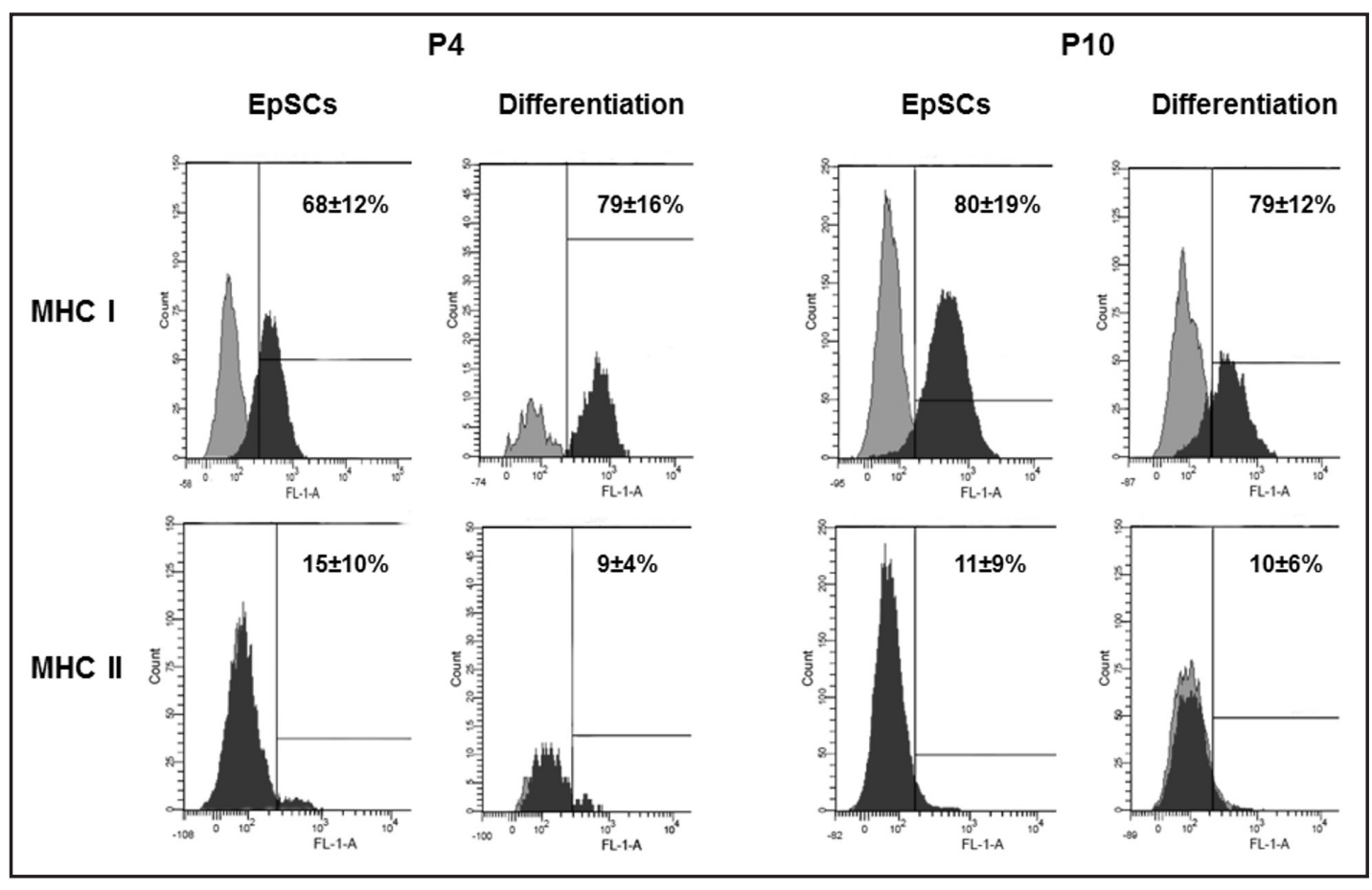

Fig. 3. Immunophenotypic characterization of skin-derived epithelial-like stem cells (EpSCs) at passage (P) 4 and 10. Flow cytometery was performed to assess the number of undifferentiated EpSCs and differentiated cells (Diff) expressing major histocompatibility complex (MHC) I and MHC II. The histograms show relative number of live cells versus fluorescence intensity with isotype control staining (light gray) and marker antibody staining (dark). Data represent the mean percentage of six samples \pm standard deviation.

Fig. 4. Differentiation of epitheliallike stem cells (EpSCs) into keratinocytes at passage (P) 4 and 10. Immunohistochemistry was performed on adherent undifferentiated and differentiated cells using markers including, CK14, Pan CK, Wide CK and casein kinase $2 \beta$. Relevant isotype controls were also included. After Hematoxylin counterstaining, pictures were taken using a digital microscope camera, at 400x magnification. Arrows indicate positive staining and bars represent $50 \mu \mathrm{m}$.

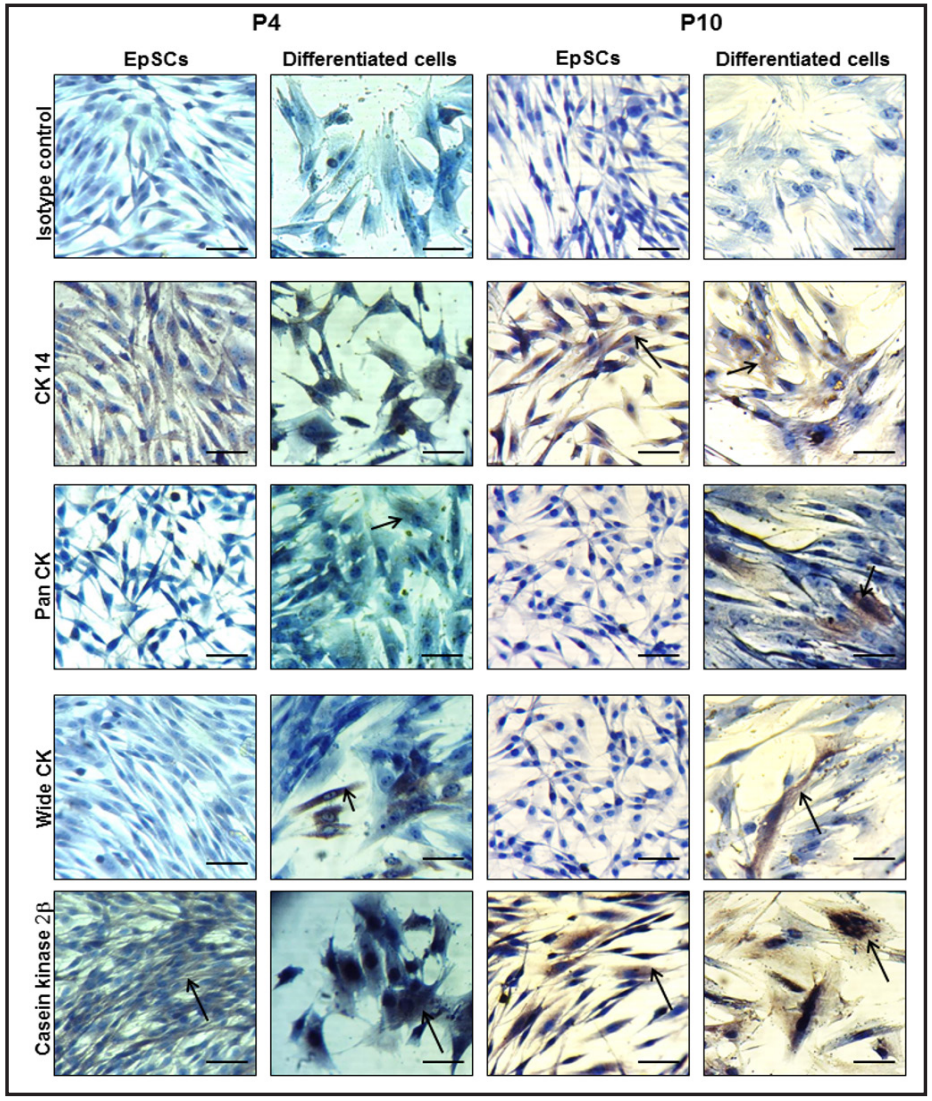




\section{Purification of EpSCS}

Cellular contamination was detected in one out of the six skin samples. The impurity was detected at $\mathrm{P}_{4}$ on adherent plates and remained present over time (Fig. 5). Both the average number of spheres/well and cells/sphere from seeding at clonal densities i.e.at 10 cells/6-well and 100 cells/6-well increased from day 4 to day 7 post-planting in pure and impure cultures (Fig. 6A and B). However, compared to pure EpSCs, the sphere forming efficiencies were significantly lower $(\mathrm{P}=0.0012)$ in impure cultures (Fig. 6C). In marked contrast to the ultralow seeding densities, higher seeding densities (i.e.at 1000 cells/6well) resulted in unsuccessful purification (Fig. 7B) and a decrease in the number of spheres over time (data not shown), yet with an increase in sphere size (Fig. 6D). The keratinocyte impurity was confirmed by IHC as shown in Fig. 7A based on positive expression of a panel of selected appropriate markers as described (CK 14, Pan CK, Wide CK and Casein kinase $2 \beta$ ). During the process of purification by planting at different clonal densities, the impurity was still detected in several wells derived from the 1000 cells/6-well purification (Fig. 7B). A successful purification of the cell culture was achieved by planting at a density of 10

Fig. 5. Morphology of adherent keratinocyte impurities (colonies of cobblestone shaped cells) in the epithelial-like stem cell (EpSC) isolate at passage (P) 4 and 10.
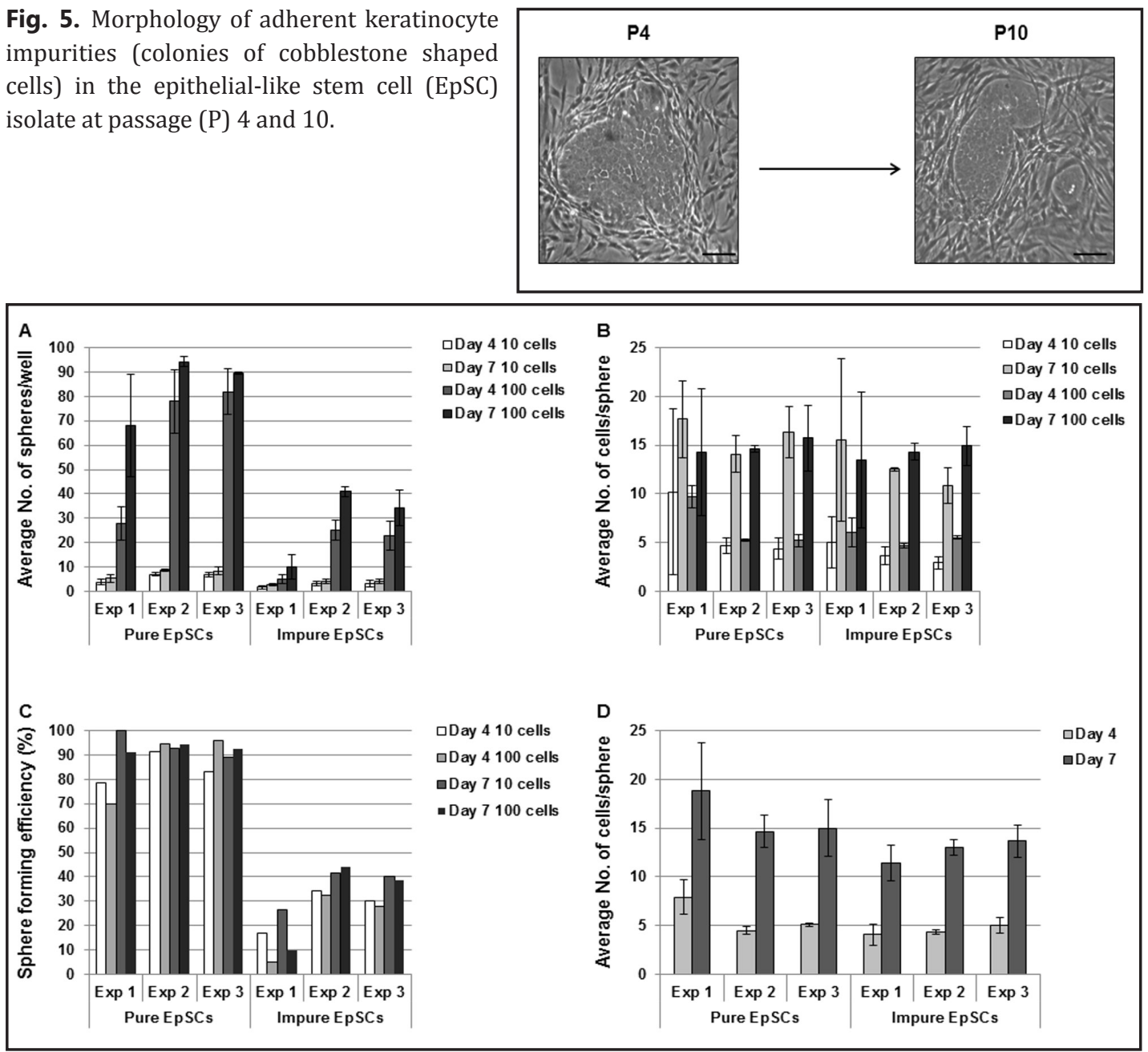

Fig. 6. Sphere forming assay for purification of the impure samples in comparison to a pure isolate. Average number of spheres/well from planting 10 cells/6-well and 100 cells/6-well (A), average number of cells/ sphere from planting of 10 and 100 cells/6-well (B), sphere forming efficiency in percentage of cells that were able to form a sphere (C) and average number of cells/sphere from planting of 1000 cells/6-well (D) were compared between pure and impure epithelial-like stem cells (EpSCs). Systematic counts were done at 200x magnification. Data represent the average values of 3 wells per experiment \pm standard deviation. 
Fig. 7. Immunohistochemistry of adherent epithelial-like stem cells (EpSCs) with keratinocyte impurity (A) before purification, keratinocyte detected in two of the 100 cells $/ \mathrm{cm}^{2}$ purification (B), purified EpSCs derived from seeding 10 EpSCs $/ \mathrm{cm}^{2}$ (C) and from 1 cell $/ \mathrm{cm}^{2}$ (D). Pictures in rows show Isotype control and markers used as CK 14, Pan CK, Wide $\mathrm{CK}$ and Casein kinase $2 \beta$. Arrows indicate positive reaction in the cytoplasm at 400x magnification. Scale bars represent $50 \mu \mathrm{m}$.

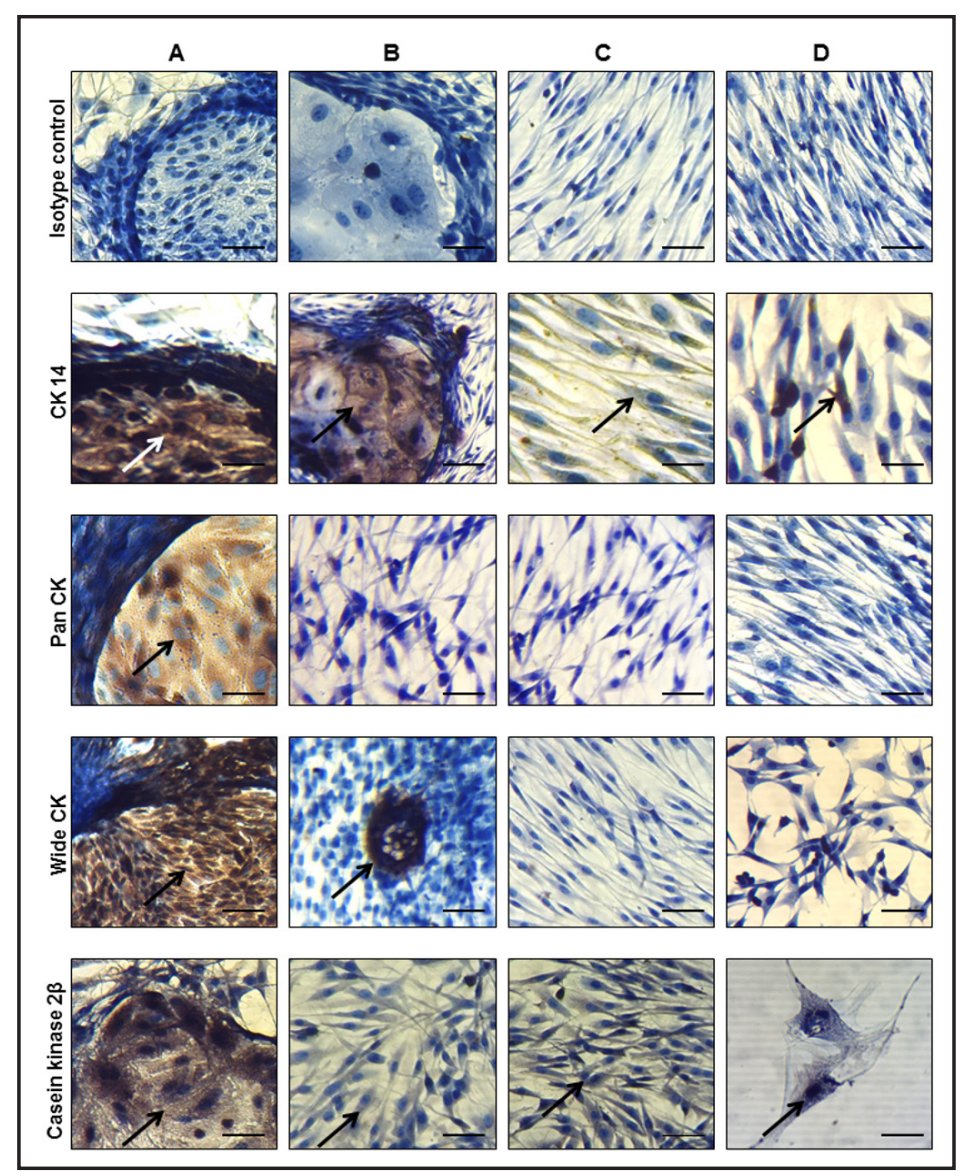

cells $/ \mathrm{cm}^{2}$ (Fig. 7C) and 1 cell/ $\mathrm{cm}^{2}$ (Fig. 7D). This was confirmed by the spindle shaped cell morphology and negative expression of Pan CK and Wide CK.

\section{Discussion}

Being the body's largest organ, skin has been extensively used to study adult/somatic stem cells [31]. In particular, it has been suggested as the main source of epithelial-like stem cells (EpSCs) [15, 32]. Besides the presence of somatic stem cells in hair follicles and dermis, the epidermis also contains a compartment of stem cells $[9,14]$ which are of different maturity levels. However, there is no common criterion that allows to recognize individual stem cells with confidence [14]. In a human skin study, it was identified that the latter stem cells are firmly adherent to the basal lamina and account for $10 \%$ of the cells in the basal layer at the dermal-epidermal junction [29]. So far EpSCs have been obtained either by dedifferentiating adult epidermal cells [33, 34], or by inducing pluripotent stem cells [35], or by their direct harvest from the epidermis $[9,36]$. Isolation of sphere-forming skin-derived epithelial cells from suspension culture has been described already in 1986 [37]. Such a suspension commonly consists of stem cells and their transit-amplifying progeny [38]. A potential disadvantage of this isolation technique is the likely contamination with other cell types due to adult cells surviving between the sphere-forming stem cells [26]. So far, sphere formation was successful both from bulk skin tissue-derived cell suspension [6] and from culture of epidermis-derived cells at a clonal density [9] on ultralow attachment plates.

In the current study, skin was harvested from six horses and an average sphere-forming efficiency of $0.53 \pm 0.28 \%$ of these seeded cells was demonstrated. As is the case for primary mammary cells [26], most of the primary skin-derived epithelial cells died in suspension culture. It has to be mentioned, that although the starting material from all donors had 
the same size, the initial cell seeding density varied $0.21 \times 10^{6}$ cells between donors and might have caused a variation in sphere forming efficiency at the first cycle. In agreement with our results, it has been described that $0.4 \%$ of the seeded mammary cells were able to form mammospheres in humans [26] a percentage which was higher in horses ranging from 0.8 to $3.2 \%$ depending on the lactation stage [27]. Moreover, subsequent generations of spheres could be generated from P4 and P10 with a relatively constant sphere-forming efficiency of almost all purified cells (data not shown). This finding corroborates a previous study [9] and is indicative for the fact that each sphere contained approximately one sphereinitiating cell. Thus, the self-renewal and clonal expansion capacities of the isolated cells being main characteristics of stem cells, was clearly demonstrated [38]. Visual examination of suspension culture revealed that, although spheres could also grow in the differentiation medium, their number was significantly lower compared to that observed in the EpSC medium during both second and third sphere cycles. This clearly indicated an overall lower cell survival of the more differentiated EpSC progeny or of the undifferentiated EpSCs in differentiation medium. Based on the first hypothesis, this difference could be attributed to the fact that once skin-derived precursor cells are differentiated, they lose the typical stem cell properties and their survival in suspension is substantially reduced [25]. The strong correlation between the numbers of cell units/field and of spheres/field was an indicator that most of the skin-derived purified EpSCs resulted in sphere formation. Additionally, the number of cells/sphere increased from day 4 to day 7 post seeding which indicated that clonal expansion of cells within the sphere occurred up to P10.

Cellular contamination was noticed in one of the six horse skin isolates. Cell contamination is usually difficult to detect, and consequently is a potentially major culture problem than the problems caused by other types of biological contamination [39]. In the present study, cellular impurities were clearly visible microscopically based on morphology and on IHC staining for keratinocytes. This contamination could be noticed from P4 on and the level of impurity increased during passaging. Nevertheless, it has been reported that serial passaging would rather eliminate more committed progenitors and select for selfrenewing stem cells [38]. For that reason, cells were seeded at ultralow clonal densities varying from 1 cell to 100 cells per $\mathrm{cm}^{2}$ on 6-well ultralow attachment plates followed by adherent culture. Here, IHC staining demonstrated that only the lowest densities allowed EpSCs to survive and removed the cellular impurities from culture. Although the purification in the present study consisted of cells from only one donor, the experiment was performed three times (in triplicate for each time point) and generated consistent results. Nevertheless, future studies should confirm the reported purification technique in different isolates with different degrees of impurities.

Another key finding of the present study pertains to the immunophenotypic characterization of EpSCs by flow cytometry. Expression of Major Histocompatibility Complex (MHC) I and MCH II was evaluated on equine EpSCs and their differentiated progeny. These data showed that most EpSCs and differentiated cells expressed MHC I and only a few cells expressed MHC II. This result is in contrast with a previous report using equine EpSCs [9], where only few cells expressed MCH I. It has to be mentioned though, that in the present study only live cells were gated, because a rather high death rate was present during measurement, whereas in the previous study all cells were measured including the dead ones. Nevertheless, the high number of cells expressing MHC I in this study is also in contrast with a previous study on differentiated keratinocytes, where a low number of cells expressing this marker was reported in a sub-population of basal human keratinocytes [40]. It is known that the rejection response to grafted tissues/cells is caused by cell surface molecules that induce antigenic stimulus. MHC molecules are one of the families within the highly heterogeneous group of transplantation antigens that have been described so far [41]. While MHC I antigens are present on all nucleated cells and are involved in antigen presenting activities [42], MHC II are expressed on activated B-lymphocytes, macrophages, dendritic cells and epithelial cells [43] and involved in graft rejection [44]. Therefore, the low number of undifferentiated as well as differentiated EpSCs expressing MHC II suggest 
that these cells might be attractive candidate cells for allogenic transplantation in horses. Nevertheless, future studies will have to confirm this statement and should focus on the relative expression levels (per cell) of these and other immunomodulating molecules as well.

In conclusion, the present study reports sphere formation as a valuable tool to purify stem cells in skin cell cultures upon isolation and after serial passaging. Further research should focus on the optimization and validation of this purification strategy of stem cells cultured from skin as well as from other tissues.

\section{Acknowledgement}

This study was supported by Global Stem cell Technology and Pell Cell Medicals. Bizunesh M. Borena was supported by a grant of the Netherlands University Foundation for International Cooperation (NUFFIC).

\section{Disclosure Statement}

SYB and JHS declare competing financial interests and Pell Cell Medicals declares a patent with number W02014029778.

\section{References}

1 Hoynowski SM, Fry MM, Gardner BM, Leming MT, Tucker JR, Black L, Sand T, Mitchell KE: Characterization and differentiation of equine umbilical cord-derived matrix cells. Biochem Biophys Res Commun 2007;362:347-53.

2 Pittenger MF, Mackay AM, Beck SC, Jaiswal RK, Douglas R, Mosca JD, Moorman MA, Simonetti DW, Craig S, Marshak DR: Multilineage potential of adult human mesenchymal stem cells. Science 1999;284:143-147.

- 3 Jiang Y, Jahagirdar BN, Reinhardt RL, Schwartz RE, Keene CD, Ortiz-Gonzalez XR, Reyes M, Lenvik T, Lund T, Blackstad M, Du J, Aldrich S, Lisberg A, Low WC Largaesp- ada DA, Verfaillie CM: Pluripotency of mesenchymal stem cells derived from adult marrow. Nature 2002;418:41-49.

- Zuk PA, Zhu M, Ashjian P, DeUgarte DA, Huang J., Mizuno H, Alfonso ZC, Fraser JK, Benhaim P, Hedrick MH: Human adipose tissue is a source of multipotent stem cells. Mol Biol Cell 2002;13:4279-4295.

5 Spaas JH, CD Schauwer, P Cornillie, E Meyer, AV Soom and GR Van de Walle: Culture and characterisation of equine peripheral blood mesenchymal stromal cells. Vet J 2013;195:107-113.

6 Toma JG, Akhavan M, Fernandes KJ, Barnabe-Heider F, Sadikot A, Kaplan DR, Miller FD: Isolation of multipotent adult stem cells from the dermis of mammalian skin. Nat Cell Biol 2001;23:778-784. Barthel R, Aberdam D: Epidermal stem cells. J Eur Acad Dermatol Venereol 2005;19:405-413.

Toma JG, McKenzie IA, Baqli D, Miller FD: Isolation and characterization of multipotent skin derived precursors from human skin. Stem Cells 2005;23:727-737.

-9 Broeckx SY, Maes S, Martinello T, Aerts D, Chiers K, Marien T, Patruno M, Franco-Obregon A, Spaas JH: Equine Epidermis: a source of Epithelial-like Stem/Progenitor cells with in vitro and in vivo regenerative capacities. Stem Cells Dev 2014;23:1134-1148.

10 Braun KM, Niemann C, Jensen UB, Sundberg JP, Silva-Vargas V, Watt FM: Manipulation of stem cell proliferation and lineage commitment: visualization of label-retaining cells in whole mounts of mouse epidermis. Development 2003;130: 5241-5255.

11 Lavker RM, Sun TT: Epidermal stem cells. Properties, markers, and location. Proc Natl Acad Sci USA 2000;97:13473-13475.

-12 Niemann C, Watt FM: Designer skin: lineage commitment in postanatal epidermis. Trends Cell Biol 2002;12:185-192.

13 Chen M, Przyborowski M, Berthiaume F: Stem cells for skin tissue engineering and wound healing. Crit Rev Biomed Eng 2009;37:399-421.

14 Terskikh VV, Vasil'ev AV: Epidermal stem cells. Izv Akad Nauk Ser Biol 2001;6:738-744.

15 Staniszewska M, Słuczanowska-Głąbowska S, Drukała J: Stem cells and skin regeneration. Folia Histochem Cytobiol 2011;49:375-80.

16 Cotsarelis G, Sun TT, Lavker RM: Label retaining cells reside in the bulge area of pilosebaceous unit: implications for follicular stem cells, hair cycle and skin carcinogenesis. Cell 1999;61:1329-1337.

17 Taylor G, Lehrer MS, Jensen PJ, Sun T-T, Lavker RM: Involvement of follicular stem cells in forming not only the follicle but also the epidermis. Cell 2000;102: 451-461. 
Borena et al.: Purification of Epithelial-Like Stem Cells from Equine Skin

18 Ito M, Liu Y, Yang Z, Nguyen J, Liang F, Morris RJ, Cotsarelis G: Stem cells in the hairfollicle bulge contribute to wound repair but not to homeostasis of the epidermis. Nat Med 2005;11:1351-1354.

19 Langton AK, Herrick SE, Headon DJ: An extended epidermal response heals cutaneous wounds in the absence of a hairfollicle stem cell contribution. J Invest Dermatol 2008;128:1311-1318.

20 Blau HM, Brazelton TR, Weimann JM: The evolving concept of a stem cell: Entity or function? Cell 2001;105:829-841.

-21 Yano S, Ito Y, Fujimoto M, Hamazaki TS, Tamaki K, Okochi H: Characterizaton and localization of side population cells from mouse skin. Stem Cells 2005;23:834-841.

22 Rochat A, Kobayashi K, Barrandon Y: Location of stem cells of human hair follicle by conal analysis. Cell 1994;76:1063-1073.

23 Rochat A, Kobayashi K, Barrandon Y: Location of stem cells of human hair follicle by conal analysis. Cell 1994;76:1063-1073.

24 Li A, Pouliot N, Redvers R, Kaur P: Extensive tissue regenerative capacity of neonatal human keratinocyte stem cells and their progeny. J Clin Invest 2004;113:390-400.

-25 Ruetz M, Knauer T,Gallinat S, Wenck H, Achterberg V, Maerz A, Deppert W, Knott A: A novel niche for skin derived precursors in non-follicular skin. J Dermatol Sci 2013;69:132-139.

-26 Dontu G, Abdallh WM, Foley JM, Jackson KW, Clarke MF, Kwamura MJ, Wicha MS: In vtro propagation and transcriptional profiling of human mammary stem/progenitor cells. Genes Dev 2003;17:1253-1270.

27 Spaas JH, K Chiers, L Bussche, C Burvenich and GR Van de Walle: Stem/progenitor cells in non-lactating versus lactating equine mammary gland. Stem Cells Dev 2012;21:3055-3067.

28 Martinello T, Bronzini I, Maccatrozzo L, Iacopetti I, Sampaolesi M, Mascarello F, Patruno M: Cryopreservation does not affect the stem characteristics of multipotent cells isolated from equine peripheral blood. Tissue Eng Part C Methods 2010;16:771-781.

-29 Papini S, Cecchetti D, Campani D, Fitzagerald W, Grivel JC, Chen S, Margolis L, Rovoltella RP: Isolation and clonal analysis of human epidermal keratinocyte stem cells in long term culture. Stem Cells 2003;21:481494.

-30 Deshiere A, Duchemin-Pelletier E, Spreux E, Ciais D, Combes F, Vandernbrouck Y, Coute Y, Mikaelian I, Giusiano S, Charpin C, Cochet C, Filhol O: Unbalanced expression of CK2kinase subunits is sufficient to drive epithelial to mesenchymal transition by snail1 induction. Oncogene 2013;32:1373-1383.

-31 Li L, Fukunaga-Kalabis M, Herlyn M: Isolation, characterization, and differentiation of human multipotent dermal stem cells. Methods Mol Biol 2013;989:235-246.

32 Grandi F, Firmo BF, Colodel MM, Rocha RM, Werner J, Rocha NS: The importance of follicular stem cells in veterinary medicine in the context of skin tumours. Vet Dermatol 2012;23:81-82.

33 Li H, Fu X, Zhang L, Sun T, Wang J: In vivo dedifferentiation of human epidermal cells. Cell Biol Int 2007;31:1436-1441.

-34 Zhao Z, Zhang C, Fu X, Yang R, Peng C, Gu T, Sui Z, Wang C, Liu C: Differentiated epidermal cells regain the ability to regenerate a skin equivalent by increasing the level of beta-catenin in the cells. Cells Tissues Organs 2012;196:353-361.

-35 Li YT, Liu DW, Liu DM, Mao YG, Peng Y, Ning P, Hu X, Zou P, Zou NH, Yu QH: Experimental study on the differentiation of human induced pluripotent tem cells into epidermal-like stem cells. Zhonghua Shao Shang Za Zhi 2012;28:274-277.

-36 Yang X, Qu L, Wang X, Zhao M, Li W, Hua J, Shi M, Moldovan N, Wang H, Dou Z: Plasticity of epidermal adult stem cells derived from adult goat ear skin. Mol Reprod Dev 2007;74:386-96.

-37 Soule HD, McGrath CM: A simplified method for passage and long-term growth of human mammary epithelial cells. In vitro cellular \& developmental biology 1986;22:6-12.

-38 Pastrana E, Silva-Vargas V, Doetsch F: Eyes wide open: a critical review of sphere formation as an assay for stem cells. Cell Stem Cell 2011;8:486-497.

-39 Fogh J, Holmgren NB, Ludovici PP: A review of cell culture contamination. In Vtro 1971;7:26-41.

40 Matic M: A subpopulation of human basal keratinocytes has a low/negative MHC class I expression. Hum Immunol 2005;66:962-968.

41 Ayala GMA, Gonzalez YB, Lopez FAL, Guani GE: The major histocompatibility complex in transplantation. J Transplant 2012;2012:84214.

42 King A, Hiby SE, Gardner L, Joseph S, Bowen JM, Verma S, Burrows TD, Loke YW: Recognition of trophoblast HLA class I molecules by dedidual NK cell receptors-a review. Plancenta 2000;21:s81-s85.

43 Klein J, Sato A: Advances in immunology: the HLA system (second of two parts). N Engl J Med 2000;343:782-786.

44 Natarajan K, Dimasi N, Wang J, Mariuzza RA, Margulies DH: Structure and function of natural killer cell receptors: multiple molecular solutions to self, nonself discrimination. Ann Rev Immunol 2002;20:853885. 